\title{
LA CONTRIBUCIÓN DE LA CIUDAD DE BURGOS Y SU JURISDICCIÓN A LA PACIFICACIÓN DE LAS ALPUJARRAS, 1569-1570
}

\author{
Ángela Pereda López \\ Universidad de Burgos
}

RESUMEN. El levantamiento de la población morisca de la zona de las Alpujarras, a finales de 1568, provocó la necesidad de formar un ejército cristiano cuyo objetivo sería el sometimiento y la pacificación de estos territorios. En un primer momento, el reclutamiento, se llevó a cabo en los lugares geográficos cercanos al foco de la crisis, pero posteriormente fue necesario acudir a otras zonas geográficas. Entre aquellos lugares se encontró Burgos que, por orden del monarca, tuvo que reunir 500 hombres para luchar bajo las órdenes de don Juan de Austria. Esta tarea no fue nada fácil, pues Burgos se encontraba inmersa en una crisis económica y demográfica que no lograba remontar. Aun así, logró formar la compañía, a cuyo frente estuvo el capitán don Sancho de Tobar. Este trabajo pretende mostrar cómo se llevó a cabo el reclutamiento de los hombres y el esfuerzo que supuso para la ciudad y su jurisdicción.

Palabras clave: Alpujarras, Burgos, guerra, moriscos, reclutamiento, siglo XVI

\begin{abstract}
The uprising of the Moorish population in the area of the Alpujarras, at the end of 1568 , caused the need to form a Christian army that would have, as its only objective, the submission and pacification of these territories. Initially this project was carried out in the geographical areas close to the focus of the crisis, but subsequently it was necessary toask to other geographical areas. Among those places was Burgos which, by order of the monarch, had to gather 500 men to fight under the orders of don Juan of Austria. This task was not easy. Burgos was immersed in an economic and demographic crisis that could not overcome. Even so, the city managed to form the company, which was led by Captain don Sancho de Tobar. This work aims to show how the recruitment of the men was carried out and the effort it involved for the city and its jurisdiction.
\end{abstract}

Keywords: Alpujarras, Burgos, war, moors, recruitment, $16^{\text {th }}$ century

Recibido: 12-05-2020. Aceptado: 16-11-2020.apereda@ubu.es 
El PRESENTE ESTUdio TIENE COMO OBJeTIVo completar lo que hasta este momento se ha venido publicando sobre la participación que la ciudad de Burgos — junto a su jurisdicción y lugares comarcanos - tuvo en el apaciguamiento de la rebelión de las Alpujarras (López Mata, 1957; González Prieto y Rodríguez, 2008). Para lograr dicho objetivo hemos visitado archivos burgaleses, el Archivo Histórico Provincial de Álava, el Archivo Histórico Provincial de Guipúzcoa, y consultado la bibliografía más destacada acerca de este hecho histórico.

Felipe II estuvo siempre preocupado por conservar la unidad religiosa en sus territorios, pero no fue una tarea fácil. El año de 1568 fue muy complicado para el monarca tanto a nivel personal como político. A nivel personal sufrió la pérdida de su heredero, el príncipe Carlos, el 24 de julio, y poco después, el 3 de octubre falleció su esposa, la reina Isabel. El monarca tuvo que afrontar estas ausencias a la vez que comprobaba que la Reforma se iba extendiendo por toda Europa sin poder frenarla, y los Países Bajos se rebelaban contra su persona, iniciándose así la denominada Guerra de los Ochenta Años. Dentro de la Península, otro frente se abría cuando los moriscos más radicales promovieron un levantamiento al que se le denominó la segunda Guerra de Granada o de las Alpujarras. Desde 1556, año en que accedió al trono Felipe II, la política conciliadora con los moriscos decayó. El monarca quiso poner fin a la colaboración de una parte de la población morisca en los asaltos de piratas con el decreto de 3 de enero de 1563, por el que se procedió al desarme de aquel grupo, y al reforzamiento, a partir de 1560, del litoral con la reforma de las fortificaciones existentes y la construcción de otras nuevas (que debido al alto coste no se llevaron a término); dichas fortificaciones evitarían los contactos entre el exterior y los moriscos. Además, el Sínodo Provincial de Granada, en septiembre de 1563, y la reunión que mantuvo el monarca con don Pedro Guerrero, arzobispo de Granada, terminó de convencerle para poner fin a la permisividad que hasta aquellos momentos había existido (Sánchez Ramos, 2000, pp. 509-511). Desde que el reino de Granada fuera conquistado, la fiscalidad entre los colonos y los moriscos fue desigual; mientras que los repobladores cristianos apenas tuvieron que abonar dinero al fisco durante la última década del siglo xv, sobre los moriscos recayeron todos los impuestos ordinarios castellanos (alcabalas, servicios...) y otros que se crearon. Tal presión fiscal que fue aumentando con el paso de los años fue otro de los aspectos que motivaron el levantamiento (Castillo Fernández y Muñoz Buendía, 2000, pp. 101-103).

A finales de diciembre de 1568, la mayoría de las tahás alpujarreñas se habían sublevado; no consideraban al monarca como su gobernante y calificaban de opresivas las instrucciones que les afectaban (Jiménez Estrella, 2004, p.162). Lo que, en principio parecía un levantamiento relativamente fácil de controlar, de unos cuatro mil rebeldes, se extendió en el tiempo — desde la Nochebuena de 1568 hasta noviembre de 1570, cuando Luis de Requesens y don Juan de Austria despidieron a sus tropas-, en territorio y en número de sublevados, poniendo en jaque al ejército de 
la Monarquía Hispánica. En enero de 1569, dos fuerzas cristianas independientes a las órdenes del marqués de Mondéjar y Los Vélez emprendieron una fuerte campaña de represión que no fue muy eficaz debido al apoyo de los musulmanes del norte de África, que enviaron armas y voluntarios (Kamen, 1997, pp. 134-135). Fernández Álvarez la define como una guerra extremadamente cruel, en la que los moriscos, en los primeros momentos, torturaron y mataron sin piedad a los cristianos que apresaron, y por su parte, las tropas reales, sobre todo en la etapa final, «llevaron la guerra a sangre y fuego» (Fernández Álvarez, 1998, p. 463). A lo largo de aquel año del 69, la rebelión fue catalogada «dentro de los delitos de lesa majestad divina y humana, y los moriscos como rebeldes contra el Rey y la Religión, traidores e infieles apóstatas», y tuvo como consecuencia la licitud de la esclavitud de los moriscos (Pérez García y Fernández Chaves, 2012, p. 241).

A lo largo del siglo Xvi se llevaron a cabo varios intentos para que la población castellana se comprometiera de manera activa en una milicia territorial. Jiménez Estrella señala que el primero de ellos fue ideado, en 1516, por Cisneros que fracasó por la oposición de la nobleza a un proyecto que podía contrarrestar su poder en favor de la corona; también fracasaron el intento de 1552, que buscó la formación de una milicia de 34.000 soldados sustentada por las ciudades, el de 1562, que procuró que se creara una milicia de 69.000 infantes y 7.900 jinetes, y el de 1565, que ofrecía a las oligarquías locales un mayor control en el nombramiento de suboficiales, el reclutamiento y la organización de las compañías (Jiménez Estrella, 2009, pp. 85-86).

La defensa del territorio hispánico sería prioritaria para la corona desde aquella sublevación; según José Contreras Gay, presentó dos rasgos novedosos: «la preocupación por la defensa del conjunto del territorio peninsular y el intento de establecer un sistema escalonado de defensa, integrado por las guarniciones militares de la periferia, por las milicias locales o compañías de socorro formadas en las poblaciones de la costa o en su proximidades [...], y la milicia general que debía levantarse en los partidos del interior de Castilla para conseguir una organización militar más racional y eficaz» (Contreras Gay, 1997, p. 613). Se pusieron en evidencia las carencias y defectos de las milicias concejiles como fuerzas de intervención en una campaña de gran transcendencia debido a su escasa preparación y disciplina, las numerosas deserciones y desórdenes que se dieron en las distintas compañías (Jiménez Estrella, 2009, p. 86).

El cabildo de la Catedral de Burgos, en enero del 69, encargó a los maestros de ceremonias y al canónigo Buenaventura de Lerma que trataran con Lorenzo Fernández, gobernador del obispado, la celebración de procesiones en las iglesias y monasterios para favorecer la fe católica y así aplacar el levantamiento de Granada y Murcia ${ }^{1}$. 
El consejo de Guerra, en febrero, calculó que serían necesarios 9.000 infantes y 900 hombres de a caballo para poder controlar la sublevación, y tan sólo se había podido reunir a 6.000 infantes (González Prieto y Rodríguez Hernández, 2004, p. 109). En verano se produjo un recrudecimiento de la rebelión. Luis de Requesens, comendador mayor de Castilla, trajo doce compañías de los tercios viejos situados en Italia: una pertenecía al tercio del Piamonte y otra al de Lombardía, y las restantes al tercio de Nápoles, tercio al que se uniría el contingente burgalés posteriormente. La dura travesía desde Italia provocó que se perdieran la mitad de los efectivos, llegando tan solo tres o cuatro compañías del tercio de Nápoles. Junto a este ejército regular combatieron milicias concejiles (Jiménez Estrella, 2004, p. 171; Tapia Garrido, 1990, p. 43).

En los primeros momentos, las fuerzas cristianas se constituyeron con hombres de los territorios más cercanos a la rebelión, pero el recrudecimiento de la guerra hizo necesario recurrir a hombres de otras zonas como Extremadura, Castilla-La Mancha, $\mathrm{y}$, posteriormente, del norte. El regimiento de la ciudad de Burgos recibió una misiva real, de 6 de noviembre de 1569, en la que se notificaba que se había enviado a don Juan de Austria a Granada y que existía necesidad de hombres para lograr el éxito: se solicitaba a Burgos y su jurisdicción la aportación de 500 infantes «de los más útiles y bien armados» — la mitad arcabuceros, una cuarta parte ballesteros y el resto piqueros - que deberían llegar a Granada a finales del mes de diciembre. La ciudad contaba con un mes para reunir a los infantes y comenzar el camino hacia su desti$n^{2}$. Ese mismo día se encomendó a Pedro de Melgosa, alférez mayor, que sacara la bandera de la ciudad y tocara los tambores para que diera comienzo el reclutamiento de hombres.

\section{Los medios: hombres, armas y dineros}

Tras recibir la orden de formar la compañía, el gobierno de la ciudad era consciente de que iba a ser una tarea difícil por la falta de hombres que padecía; muchos murieron con la peste del año 65 (González Prieto, 2006, pp. 114-155) 3 y desde el mes de julio a noviembre de 1569 se habían formado dos compañías con un total de 400 hombres. Esta situación provocó que, el ayuntamiento, reclamara una provisión real poder reclutar gente en la ciudad, su jurisdicción, y lugares de señorío (Miranda, Pancorbo y Can de Muñó), y, si no fuera posible alcanzar el número solicitado, se pudiera hacer un repartimiento sobre los dichos lugares. La ciudad tampoco contaba

2 Archivo Municipal de Burgos (en adelante AMBu), Libro de Actas, 1569, 10 de noviembre, fol. 173 v. -174 r.

3 La ciudad de Burgos, en 1565, contaba con 4.500 vecinos (entre 18.000 y 22.500 individuos) y se ha estimado que pudo perder entre un $30-35 \%$, quedando alrededor de 3.250 vecinos. 
con las armas necesarias para que los soldados fueran bien aderezados; necesitaba licencia real para que la fortaleza les proporcionara los coseletes, arcabuces, pólvora y picas necesarios, abonando aquello que se utilizara y devolviendo a la fortaleza lo que sobrara. Si no hubiera suficientes suministros, se tendrían que adquirir en los lugares de fabricación de armamento: en las provincias vascas. La urgente necesidad de reorganización del ejército en las Alpujarras facilitó que se concediera todo aquello que se había solicitado.

Las arcas municipales se encontraban muy endeudadas, pues aún no se habían terminado de pagar algunos de los gastos extraordinarios del último quinquenio (véase tabla 1); Felipe II concedió licencia para poder echar "por sisa en el vino que en esa dicha ciudad se vendieses y gastase $»^{4}$.

Tabla 1. Gastos que no se habían terminado de pagar durante el periodo 1565-1570

\begin{tabular}{|l|r|}
\hline \multicolumn{1}{|c|}{ Gastos 1565-1570 que no se habían terminado de pagar } & Maravedíes \\
\hline Gastos derivados de la guarda de la ciudad y arrabales durante la pestilencia & 397.600 \\
\hline $\begin{array}{l}\text { Recibimiento de la reina Isabel, réditos de los censos que se tomaron, aunque al final la reina no llegó a entrar } \\
\text { en la ciudad }\end{array}$ & 1.101 .772 \\
\hline Honras y exequias del príncipe Carlos fallecido el 24 de julio de 1568 & 318.884 \\
\hline Honras y exequias de la reina Isabel fallecida el 3 de octubre de 1568 & 220.040 \\
\hline Planta de árboles en los montes & 139.225 \\
\hline Total $^{5}$ & 2.177 .521 \\
\hline
\end{tabular}

Fuente: AMBu, Libro de Actas Municipales, 1569.

Burgos se había visto obligada a realizar dos aportes de hombres aquel mismo año. El primero de ellos, cuando el alférez Nuño González y el cabo de escuadra Gaspar Cerón se presentaron en el pleno de 12 de junio para mostrar una conducta; según esta, el duque de Medinaceli, virrey y capitán general del reino de Navarra, informaba de la facultad que tenía para levantar 200 soldados con el fin de «rehacer las compañías ordinarias de infantería que se encontraban en el dicho reino» y también la instrucción de cómo debían llevarse a cabo ${ }^{6}$. Mes y medio más tarde, el 23 de agosto, se presentó el capitán Carlos de Tapia con otra provisión para poder levantar otros 200 infantes $^{7}$; una vez reunidos se pusieron bajo la bandera del capitán de infantería Francisco López de Padilla y partieron hacia Vitoria. Allí se pondrían bajo las órdenes de Juan de Solís, maestre de campo del ejército que se estaba formando

$4 \quad \mathrm{AMBu}$, Libro de Actas, 1569, 26 de mayo, fol. $69 \mathrm{v}$.

5 La provisión real arroja un montante de deuda de $2.127 .520 \mathrm{mrs}$., cifra inferior a la real, en 50.000 mrs.

$6 \quad \mathrm{AMBu}$, Libro de Actas, 1569, 12 de julio, fol. 111 r.-111v.

$7 \quad$ AMBu, Libro de Actas, 1569, 23 de agosto, fol. 143 r-144 r. 
para entrar en Francia, a instancias del «cristianísimo rey muy caro y muy amado hermano», haciendo referencia a Carlos IX, inmerso en las denominadas guerras de religión del país vecino.

El sistema de reclutamiento puesto en marcha fue el de comisión, planificado directamente por los gobiernos, que eran los que nombraban a los capitanes y decidían a qué lugares iba a afectar la recluta. La monarquía era la única institución que podía levantar gente en todo el territorio y derivar esta acción mediante cédulas y provisiones; sin sus órdenes no se podían enarbolar banderas ni tocar «cajas» o tambores, dos de los elementos públicos de los alistamientos controlados por las autoridades locales. El reclutamiento voluntario hasta, aproximadamente, 1580, no presionó excesivamente a los municipios por tener escasos costes directos, pero a partir de esta fecha y como consecuencia de las crisis demográficas se comenzaron a tener serios problemas para poder juntar hombres por propia voluntad (Quatrefages, 2015, pp. 124-129; Rodríguez Hernández, 2015, pp.185-216). Las dos levas que sumaron 400 hombres hacían difícil reunir a otros 500 hombres en edad de combatir, y supusieron una sangría demográfica.

El coste de los ejércitos de Flandes era totalmente asumido por la Hacienda real; para el caso que nos ocupa, la guerra de las Alpujarras, se repartió entre la Hacienda y el concejo burgalés. Al frente de la formación debía estar el regidor Diego Martínez de Soria Lerma, que no pudo asumirlo por encontrarse desempeñando el cargo de corregidor en las Cuatro Villas de la Costa. El 16 de noviembre, Felipe II expidió una conducta o patente para don Sancho de Tobar $^{8}$ en la que se especificaba que había sido elegido por capitán de los infantes que debía reclutar en la ciudad de Burgos y los lugares de su tierra. Entre los puntos contenidos se destacaba que los soldados tendrían asignado un sueldo mensual igual al asignado en Italia; para final de año tendrían que haber llegado a la ciudad de Granada, con la obligación de aumentar, si se pudiera, el número de hombres según se fuera avanzando hacia el sur; misión del capitán era mantener bien disciplinada a la compañía, evitando desórdenes; y se ordenaba a todas las ciudades, villas y lugares por donde debían pasar que ofrecieran aposento y todo lo necesario a los hombres y a las bestias de guía, a precios justos. Tobar aceptó, a pesar de «tener años y muchos hijos» ${ }^{9}$, y recibió de la municipalidad 1.000 ducados (con la obligación de devolverlos transcurridos dos años) para que pudiera llevar a buen término su labor de recluta ${ }^{10}$.

Lo primero que hizo el capitán Tobar fue encargar una nueva bandera, bajo la cual partirían los soldados burgaleses puesto que el alférez mayor no quería entregar

$8 \quad$ AMBu, Libro de Actas, 1569, 7 diciembre, fol. 196 r.-v.; C1-7-16-14, Madrid, 16 de noviembre de 1569.

$9 \quad$ AMBu, Libro de Actas, 1569, 19 y 22 de noviembre, fol. 178 v-180 r.

10 AMBu, Libro de Actas, 1569, 17 de diciembre, fol. 206 r. 
la que tenía a su cargo. La ciudad tampoco disponía de pífanos ni de tambores y era necesario buscar dos pífanos y cuatro tambores que fueran «muy buenos y con buenas cajas» ${ }^{11}$.

\section{a) El repartimiento como solución a la falta de voluntarios y el descontento generado}

La ciudad, a 7 de diciembre, tan sólo había podido reunir 150 efectivos, aun dando a muchos de ellos 4 ducados adelantados, además de las armas que eran precisas y alojándolos a su costa, por lo que solicitó poder hacer un repartimiento. El proceso de recluta no debía durar más de veinte días; si se sobrepasaba este tiempo, como ocurrió en el caso que estudiamos, podía derivar en posibles deserciones y en la imposición de una carga excesiva en la comarca donde se alojaban (Thompson, 2003, p. 22). Una cédula real daba facultad a Burgos para realizar el repartimiento en los lugares de su jurisdicción, comarcarnos y de señorío. El procurador mayor de la ciudad, Octaviano de Encinas, manifestó su disconformidad, pero no había otra solución para poder cumplir. Miranda y Pancorbo enviaron los infantes correspondientes pagados y armados, mientras que en el resto de los lugares fue muy complicado ante la negativa de sus ayuntamientos basada en la falta de hombres y dinero. Este reclutamiento forzoso bajo la dirección y organización de las autoridades locales se convirtió en una forma encubierta de fiscalidad indirecta sobre la población (Jiménez Estrella, 2009, p. 90).

Los datos demográficos fiables para conocer el número de vecinos en el siglo XVI son escasísimos, quizá los más exactos sean las averiguaciones de las alcabalas para Castilla que estudió Pilar Zabala, con tres series: 1551-1564, 1579-1584 y 1590-1595 (Zabala Aguirre, 2000). Para realizar una comparación entre habitantes y el número de hombres repartidos, hemos tomado la serie segunda, 1579-1580. Se ha descartado la primera por ser anterior a la peste de 1565 que tantos estragos hizo en la población, y la tercera por estar más alejada del periodo estudiado. Aun así, la serie elegida podría mostrar cierta recuperación demográfica tras la epidemia y las consecuencias de tres levas seguidas de 1569, que habría que tener en cuenta. En la tabla siguiente aparece reflejado, por un lado, el número de poblaciones y vecinos resultado de la averiguación de alcabalas pertenecientes a la merindad o jurisdicción donde se realizó el repartimiento y, por otro, el número de infantes requeridos, lo que supuso la paga de los dos meses por cada uno (80 reales, a excepción de la Merindad de la Bureba y la Merindad del Río Ubierna, que debían abonar 88 reales), y la proporción del número de infantes repartidos en relación con los vecinos del lugar, una vez obtenidos todos los datos (vid. Tabla 2). 
Tabla 2. Comparativa de la averiguación de alcabalas (1579-1584) y lo que supuso el repartimiento de infantes de 1569 para la formación de la compañía burgalesa

\begin{tabular}{|c|c|c|c|c|c|}
\hline \multicolumn{3}{|c|}{ Averiguación de alcabalas 1579-1584 } & \multicolumn{3}{|c|}{ Repartimiento de infantes } \\
\hline Merindad o jurisdicción & $\begin{array}{c}\mathrm{N}^{\circ} \text { de } \\
\text { pueblos }\end{array}$ & $\begin{array}{l}N^{\circ} \text { de } \\
\text { Vecinos }\end{array}$ & $\begin{array}{l}\text { Infantes } \\
\text { repartidos }\end{array}$ & Maravedíes & $\begin{array}{l}\text { Proporción aprox. } \\
\text { infantes/vecinos }\end{array}$ \\
\hline Alfoz de Burgos & 45 & 1.655 & 49 & 133.280 & 1 por cada 34 \\
\hline Arlanzón & 3 & 151 & 2 & 5.440 & 1 por cada 75,5 \\
\hline Covarrubias & 1 & 453 & 20 & 54.400 & 1 por cada 22,5 \\
\hline Juarros y la Mata & 19 & 699 & 9 & 24.480 & 1 por cada 77,5 \\
\hline Merindad de Castrojeriz & 13 & 1.576 & 58,5 & 159.120 & 1 por cada 50,5 \\
\hline Merindad de Cerrato & 1 & 205 & 6 & 16.320 & 1 por cada 34 \\
\hline Merindad de Montes & 11 & 370 & 7 & 19.040 & 1 por cada 53 \\
\hline Merindad de Muñó & 14 & 1.523 & 32,5 & 88.400 & 1 por cada 47,5 \\
\hline Oña & 1 & 179 & 2 & 5.440 & 1 por cada 89,5 \\
\hline Señorío de Burgos & 9 & 1.324 & 50,5 & 137.360 & 1 por cada 26 \\
\hline Merindad de la Bureba & & & 21 & 62.832 & \\
\hline Merindad del Río Ubierna & & & 15 & 44.880 & \\
\hline Villafranca Montes de 0ca & & & 4 & 10.880 & \\
\hline Señorío de Burgos & & & 32,5 & 88.400 & \\
\hline Totales & & & 309 & 850.272 & \\
\hline
\end{tabular}

Fuente: Elaboración propia a partir de Zabala Aguirre, 2002, y AMBu, HI-1300. 1570

Se repartieron 309 infantes, que hasta completar los 534 supusieron el 58\%; los demás fueron alistados por comisión en la ciudad de Burgos, a excepción del capitán, capellán (con la compañía viajó Lazario, cura en la iglesia de San Gil ${ }^{12}$ ) y cirujano. La aplicación del repartimiento tuvo como consecuencia la protesta de algunas de las localidades. En el alfoz de Burgos, contamos con algunos ejemplos. En Marmellar de Arriba, su regidor Juan de Agüero solicitó quedar liberado de la aportación de medio infante basado en que tenía dieciséis vecinos, entre los cuales estaban incluidas las viudas y seis hidalgos que, por su condición, quedaban exentos del repartimiento ${ }^{13}$. Pero si acudimos a la averiguación de 1579-1584, Marmellar contaba con 53 vecinos; se puede pensar que la epidemia de peste y la contribución en otras levas provocó un significativo descenso demográfico o que se intentara falsear la realidad para eludir la obligación. El alcalde de Quintanilla de las Carretas manifestó la imposibilidad de contribuir con un cuarto de hombre asignado por contar tan solo con cinco vecinos,

12 AMBu, Libro de Actas, 1569, 13 de diciembre, fol. $204 \mathrm{v}$.

13 AMBu, Documentos Guerra de Granada, C2-8-15-4. Traslado de la carta, Burgos, 3 de enero de 1570 . 
que eran renteros de otros particulares de la encomienda de Burandón de la orden de San Juan de Jerusalén ${ }^{14}$. En este caso, coindice con el número de vecinos de la averiguación de referencia. Cardeña defendía no poder aportar los dos soldados requeridos (según el repartimiento, un infante y medio), por lo que solicitó ser eximido ${ }^{15}$; la averiguación ofrecía el dato de 60 vecinos.

Otros casos los encontramos dentro de la Merindad de Muñó: Presencio, Hontoria de la Cantera, Madrigal, Las Hormazas, Estepar, Frandovinez, y Can de Muñó. La villa de Presencio se basó en el descenso de población tras la peste y en la contribución de hombres a anteriores compañías ${ }^{16}$; se les solicitó cinco infantes, con una población de alrededor de 187 vecinos. El concejo de Hontoria de la Cantera notificó que no se había alistado nadie. Ante tal hecho, el regimiento anunció complementar el salario con un ducado más al mes y con el compromiso de que las tierras del que se alistara fueran cultivadas sin ningún coste; aun así solo se inscribió Juan de Mata ${ }^{17}$.

Madrigal del Monte pidió ser exonerado de la contribución del medio soldado debido al empobrecimiento que había sufrido como consecuencia de la peste, de las plagas de oruga y langosta que habían arruinado los pastos - las malas cosechas habían dejado sin pan a los vecinos y sin paja a sus bueyes y vacas-. Su población, excluidos clérigos y viudas, no llegaba a 30 vecinos, cifra que justificaba su solicitud $^{18}$ : dato bastante menor que el ofrecido por la averiguación, 47 vecinos.

Otras poblaciones como Las Hormazas ${ }^{19}$ y las villas de Estepar y Frandovinez deseaban liberarse de la contribución de un infante cada una por no estar dentro de la jurisdicción de la ciudad de Burgos y por pertenecer a la de la villa de Muñó ${ }^{20}$. Según la averiguación de 1579-1584, Estepar contaba con 41 vecinos y Frandovinez con 42. Fernando Álvarez del Castillo, en nombre de los lugares de la jurisdicción de Can de Muñó, se negó a entregar los casi 30 soldados solicitados puesto que sus hombres se dedicaban a la labranza y no estaban formados para el oficio de la guerra; la solución propuesta fue buscar infantes en otras zonas y hacerse cargo de los gastos de los dos soldados repartidos ${ }^{21}$.

El regimiento de la villa de Villafranca Montes de Oca, y su jurisdicción, defendieron no estar sujetos a la autoridad de la ciudad de Burgos para poder excluirse de la contribución de cuatro soldados ${ }^{22}$. La villa de Covarrubias comunicó que no había va-

14 AMBu, Documentos Guerra de Granada, C2-8-15-4. Traslado de la carta, Burgos, 20 de diciembre de 1569.

15 AMBu, Documentos Guerra de Granada, C2-8-15-4. Burgos, 30 diciembre de 1569.

$16 \mathrm{AMBu}$, Asuntos de Guerra, C1-7-2-12. Presencio, 4 de diciembre de 1569.

$17 \mathrm{AMBu}$, Asuntos de Guerra, C1-7-2-12. Hontoria de la Cantera, 7 de diciembre de 1569.

18 AMBu, HI-3514. Madrigal del Monte, 7 de enero de 1570.

19 AMBu, HI-3509, Burgos, 1 de enero de 1570.

$20 \mathrm{AMBu}, \mathrm{HI}-1765$. Estepar, 3 de enero de 1570. Frandovinez, 3 de enero de 1570.

21 AMBu, Documentos Guerra de Granada, C2-8-15-4. Burgos, 10 de enero de 1570.

$22 \mathrm{AMBu}, \mathrm{HI}-874$. Villafranca Montes de Oca, 1 de enero de 1570. 
rón que quisiera alistarse y dejar sus tierras para ir a Granada; tampoco había realizado aportaciones anteriormente ${ }^{23}$. Se le pedían 20 infantes, y según la averiguación de 15791584 contaba con 453 vecinos aproximadamente, un soldado por cada 22,5 vecinos.

Los testimonios aquí presentados son una muestra de la dificultad que supuso cumplir la orden real; la peste y los continuos reclutamientos habían propiciado una escasez de varones de entre 20 y 40 años que tardaría mucho tiempo en encontrar un equilibrio. La urbe contaba por entonces con unos 3.250 vecinos y consiguió aportar 222 infantes mediante comisión, lo que supuso un aporte de un infante por cada 14,5 vecinos. Esta cifra no es totalmente fiable si tenemos en cuenta que una parte de estos hombres no eran originarios de la ciudad y su provincia, sino que llegaron para alistarse voluntariamente desde otros puntos geográficos en busca de una salida económica y social. Con todos estos datos podemos comprobar que la ciudad es la que más infantes aporta por vecino con un $42 \%$, le siguen los lugares comarcanos con un $33,3 \%$, los lugares de señorío con un 15,5\% y por último la jurisdicción de Burgos con un $9,2 \%$ de la contribución.

\section{b) El alojamiento de los soldados hasta su partida hacia Granada}

Otra de las preocupaciones del regimiento burgalés fue dónde alojar a los soldados reclutados hasta que iniciaran su marcha hacia Granada. Mantenerlos en la ciudad no era la mejor opción, pero tampoco que lo hicieran en los pueblos comarcanos $^{24}$. El 28 de noviembre se acordó que dos escuadras de soldados fueran alojadas en la localidad de Mazuelo de Muñó (25 hombres), y en la localidad de Mazuela (20 hombres), pertenecientes a la Merindad de Muñó, aunque Mazuela era villa exenta. Cada uno de los ayuntamientos debía recibir 25 maravedíes por soldado y día de estancia; también se encomendó a los dos concejos poner a una persona que les vigilase para evitar molestias y robos a los lugareños ${ }^{25}$. El contador Francisco de Castellanos se desplazó a las distintas localidades donde se encontraban asentadas las distintas escuadras para poder comprobar si existía algún problema de convivencia y que no se gastaba más de lo estipulado ${ }^{26}$. Además de Mazuelo de Muñó y Mazuela, también dieron cobijo los pueblos de Santa María del Campo, Presencio y Mahamud.

Tan sólo tenemos constancia de un incidente punible en el comportamiento de los infantes reclutados; fue el caso del soldado Diego de Ureña que, junto con otros quince soldados y dos mujeres, se hizo pasar por alférez de la compañía para poder conseguir provisiones para su propio disfrute en Gumiel de Izán. El concejo de Tubilla del Agua, en un acto de buena fe, puesto que le habían dicho que lo necesitaban para

23 AMBu, Asuntos de Guerra, C1-7-2-12. Covarrubias, 7 de diciembre de 1569.

24 AMBu, Libro de Actas, 1569, 27 noviembre, fol. $187 \mathrm{v}$.

25 AMBu, Libro de Actas, 1569, 28 y 29 de noviembre, fol. 188 r., 190 v.

26 AMBu, Libro de Actas, 1569, 17 de diciembre, fol. $208 \mathrm{v}$. 
ir a Hontoria de la Cantera, había proporcionado a Ureña y sus secuaces una carreta con dos mulas, otras cabalgaduras para ir a caballo y poder llevar su bagaje, y no les dieron dinero porque no lo solicitaron ${ }^{27}$. El capitán Sancho de Tobar, a mediados de diciembre, otorgó poder a Francisco de Lara, para que, como su alguacil, se dirigiera a los lugares de la comarca, de unas 10 leguas alrededor de ella, persiguiera a aquellos que llamándose soldados de su compañía andaban cometiendo delitos en «deservicio de Dios nuestro Señor y de Su Majestad», y fueran castigados como se debía ${ }^{28}$.

\section{c) La compañía y su armamento ${ }^{29}$}

Al frente de los más de quinientos burgaleses estuvieron el capitán Sancho de Tobar; Juan de Salcedo por alférez; el sargento Pablo Sánchez de Carbonera; y, por capellán, Lazario, beneficiado de San Gil. Dicha compañía, que sumaba 534 hombres en total, contó con veintidós escuadras, con su correspondiente cabo de escuadra y 504 soldados, además del alférez, el sargento, el capellán, el cirujano, pífano y tambores. Tenían como misión, una vez llegados a Granada, ponerse bajo la dirección de don Juan de Austria.

El levantamiento de aquellos hombres sin proporcionarles armamento no habría tenido sentido por lo que, desde el primer momento, se comenzó a buscar todo lo necesario. Lo primero que hizo el regimiento fue dar una orden para que los habitantes que tuvieran armas las ofrecieran a la ciudad a cambio de su justo valor ${ }^{30}$. El ballestero Tamayo, junto al merino del alfoz, debía localizar arcabuces entre la población y pagar a sus propietarios su valor, pero ya apenas tenían armas y las que poseían no se encontraban en las mejores condiciones (Cuesta Nieto, 2012, p. 798). También se acordó enviar expertos y dinero a Vizcaya, Guipúzcoa y Álava, donde se fabricaban armas para su adquisición.

No se puede obviar el papel destacado por los gremios armeros vascos como casi el único recurso para surtir al ejército y la armada de la Monarquía Hispánica a lo largo de la edad moderna. Desde finales del siglo xv se había desarrollado la manufactura de armas defensivas en la zona de Marquina, de armas blancas en la de Durango y de armas de fuego portátiles en la cuenca del Deva (Carrión Arregui, 1998, p. 23). La comarca armera más importante comprendía varias localidades vizcaínas y guipuzcoanas. Como veremos más adelante, cuando se habla de Placencia como centro exportador de armas hay que entender que se hace referencia a una comunidad laboral que abarcaba Durango, Elorrio, Ermua, Marquina, Eibar, Elgóibar, Placencia, Vergara y Mondragón (Larrañaga, 1976, p. 182); puntos que aparecerán en las escri-

27 AMBu, Documentos Guerra de Granada, C2-8-15-4. Gumiel de Izán, 2 de febrero de 1570.

28 AMBu, C1-7-16-14, Burgos, 18 de diciembre de 1569.

29 AMBu, Documentos Guerra de Granada, C2-8-15-4. Sin fecha.

30 AMBu, Libro de Actas, 1569, 22 de noviembre, fol. $180 \mathrm{v}-181 \mathrm{r}$. 
turas y conciertos entre el armero Pedro de Trigueros, como representante de la ciudad burgalesa, y los distintos fabricantes vascos de armas. La fabricación tradicional de armas vasca fue elevada por Felipe II al rango de Real Fábrica de Armas, con sede en Placencia, en 1573 (Azpiazu, 1994, p. 18). Todas las armas antes de su entrega debían ser probadas por un individuo designado por el monarca pero que residiera en la región; Hernando de Aguirre, vecino de Deva, fue designado para ello en 1568 y posteriormente se encargó de organizar la fábrica, punto donde se realizaba la entrega de las armas contratadas (Aldecoa, 1976, p. 225).

Para mitigar un poco el frío invernal en el que se iba a combatir se determinó adquirir 1.200 varas de paño de Durango, o en su defecto de otra calidad, para hacer mucetas a los soldados, de manera que pudieran proteger del agua y humedad las armas y pólvora que llevaban consigo ${ }^{31}$.

La ciudad encargó a Ermo la elaboración de la pólvora necesaria para los arcabuces, comprometiéndose a entregarla a su tiempo; se adquirieron las 71 arrobas y 8 libras de plomo que tenía el joyero Tordesillas en su taller. Al ballestero Tamayo se le encomendó que fuera a la ciudad de Bilbao a comprar 125 ballestas. Tras encargar las armas, Tamayo tan solo pudo traer a Burgos las vergas (los arcos de acero), cuerdas y un carcaj con 24 pasadores para cada una de las dichas ballestas, pero no los tableros o cureñas que debían obtenerse de entre los particulares de la ciudad y su jurisdicción $^{32}$. El motivo por el cual no se habían podido traer todas las armas desde Bilbao fue la orden que Felipe II había dado, por la cual no se podía suministrar ningún arma disponible, pues todas se necesitaban para apaciguar el levantamiento morisco. Un planteamiento un tanto contradictorio puesto que Burgos, tal y como expuso al monarca, se sintió agraviada e incapaz de poder armar a los hombres de su compañía; como respuesta, el rey expidió una cédula, el 3 de diciembre, por la que las provincias de Vizcaya y Guipúzcoa debían proporcionar entre 150 y 200 arcabuces a la ciudad del Arlanzón ${ }^{33}$. Además, ordenó a la casa de la munición de la ciudad dar los 309 morriones que tenía bajo su custodia con el objetivo de que los llevasen los soldados que iban a partir para ocuparse de la rebelión de los moriscos ${ }^{34}$.

El armero Pedro de Trigueros fue el encargado de viajar a las provincias vascongadas para comprar lo necesario. Los fabricantes de armas Francisco de Uberoaga, vecino de la merindad de Busturia en Vizcaya (situada a la orilla izquierda de la ría de Mundaca), Gabriel de Ansotegui, Juan Pérez de Meave, y Martín de Lecoranguiz, se obligaron, en noviembre de 1569, a entregar para el día de Navidad al armero burgalés 50 coseletes a 6,5 ducados cada uno (121.875 maravedíes) y 200 petos tranzados a

31 AMBu, Libro de Actas, 1569, 23 de noviembre, fol. $182 \mathrm{v}$,

32 AMBu, Libro de Actas, 1569, 28 de noviembre, fol. 188 r.

33 AMBu, Libro de Actas, 1569, 26 de noviembre, fol. 186 v. y 13 de diciembre, fol. 204 v.-205 r.

34 AMBu, Libro de Actas, 1569, 17 de diciembre, fol. 208 r. y 23 de diciembre, fol. 211 v. 
18 reales cada uno (122.400 maravedíes) - se recibieron 100 petos tranzados y 100 con espaldares con otros precios más elevados - La entrega se realizaría en la villa de Marquina y Trigueros hizo entrega de 1.100 reales (37.400 maravedíes), con el compromiso de abonar el resto en el plazo de diez días ${ }^{35}$. Para poder saldar la deuda se envió desde Burgos a su hijo con caudales ${ }^{36}$. Otra obligación comprometió a los armeros Pedro de Purrúa Beitia, Martín de Lecoranguiz, Francisco de Uberuaga, Gabriel de Ansotegui, Juan Pérez de Meave, Juan de Meave, Domingo de Meave, Miguel de Beitia y Martín de Gurrola, a fabricar 1000 morriones (en la relación de gastos aparece la cifra de 500) que debían ser entregados también el día de Navidad. El precio de cada morrión se fijó en 5 reales y cuartillo y se entregó a cuenta 208 escudos de oro y 12 escudos de plata, con el compromiso de abonar lo restante a la entrega ${ }^{37}$.

Diego Ruiz de Almansa, como representante de la ciudad, manifestó que ni los coseletes ni los morriones habían sido entregados en la fecha convenida y que cada día de retraso suponía una pérdida de 12.000 maravedíes, a lo que había que sumar los gastos de alojamiento y manutención de su persona y de Trigueros. Por este motivo reclamó esa compensación por día a los armeros vascos. Estos se defendieron alegando que Hernando de Aguirre había ordenado que se dejaran de fabricar los pedidos de particulares, universidades y cabildos, entre otros, para atender la petición real de armas para la guerra de Granada, y que, además, Trigueros había realizado una ampliación de pedido que era imposible acometer; y terminaban diciendo que en el contrato no aparecía reflejada la pena de 12.000 maravedíes al día por incumplimiento. Estos dos argumentos dejaban libres de culpa a los armeros vizcaínos ${ }^{38}$.

En noviembre de 1569, también se había concertado entre el armero Trigueros y varios vecinos de Placencia - Domingo de Mendiola, Juan de Churruca, Jerónimo de Igueribar - la fabricación de 200 arcabuces con todos sus aparejos, al precio de 23 reales cada uno (782 maravedíes), que suponían 156.400 maravedíes. A mediados de enero se habían entregado 179 arcabuces: 50 arcabuces por parte de Domingo de Mendiola; 50 arcabuces de Juan de Churruca; 50 arcabuces de Martín Ibáñez de Unamuno (unidos posteriormente a este negocio); 29 arcabuces de Jerónimo de Igueribar, y en febrero se recibieron los restantes. Estos arcabuces se sumaron a otros 200, con sus frascos, frasquillos, moldes, rascadores, sacapelotas, hembrillas y baquetas que Trigueros había recogido en Vitoria a finales de 1569 de Hernando de Aguirre, por los cuales abonó 4000 ducados - a 22 reales cada arcabuz con sus aderezos - ${ }^{39}$. En esta ciudad, Pedro de Trigueros otorgó poder a su mujer, Beatriz de Grado, y a Pedro del

$35 \mathrm{AMBu}, \mathrm{C} 2-8-16$. Documentos de 1570 (sin catalogar). 20 de noviembre de 1569.

36 AMBu, Libro de Actas, 1569, 17 de diciembre, fol. 208 r.

$37 \mathrm{AMBu}, \mathrm{C} 2-8-16$. Documentos de 1570 (sin catalogar). 23 de noviembre de 1569.

38 AMBu, C2-8-16. Documentos de 1570 (sin catalogar). 28 de enero de 1570.

39 Archivo Histórico Provincial de Álava (en adelante AHPA), Protocolos Notariales, 4926, Francisco de Salvatierra, escribano, fol. 238 r. Vitoria, 27 de diciembre de 1569. AMBu, C3-1-6-2. 
Campo Salazar, trapero y vecino de Burgos, para que pudieran cobrar el sueldo que tenía estipulado por su oficio ${ }^{40}$.

Poco después, Trigueros viajó a la herrería de Goicolea, en la desembocadura del río Deva, para formalizar un contrato con Miguel Marín de Lecoranguiz y Juan Sánchez de Goicolea por el cual este último se obligaba a soltar toda el agua de la herrería para que Cristóbal de Totorica pudiera limpiar las armas destinadas a la ciudad de Burgos y no trabajar en ningún otro encargo hasta que finalizara aquella tarea. Trigueros asumió el pago de un real por cada día que el amolador trabajara en limpiar y aderezar las armas ${ }^{41}$.

Los fabricantes vascos, Martín Gabriel, Francisco de Uberoaga, Pedro de Aulegtia, Martín Miguel de Artibay y Lecoranguiz se negaron a entregar una parte de las armas en marzo de 1570 hasta que no fueran abonados unos espaldares que habían proporcionado ${ }^{42}$. Un mes más tarde, Martín de Bidarte, vecino de Marquina, excusó no haber enviado ninguna arma por estar embargadas hasta no cobrar la deuda ${ }^{43}$. Martín de Zarazate, criado de Bidarte, recibió de Trigueros, en abril de 1572, 100 reales por el transporte de cuatro cargas de armas desde Marquína a Burgos ${ }^{44}$.

Además del armamento era necesario contar con pólvora y protección; en enero de 1570, Andrés de Alvarado, caporal y cabo de escuadra de la compañía burgalesa, en nombre de Alonso Sánchez de Carboneras, sargento mayor de la misma, recibió seis barriles de pólvora que pesaron 369 libras, de las cuales se quitaron 9 libras de cada barril por la tara, lo que dejó 315 libras netas, y 340 morriones estofados y aderezados ${ }^{45}$.

No hemos podido localizar ninguna escritura que haga referencia a la adquisición de las 125 picas que llevó la compañía burgalesa, pero estamos seguros de que también provinieron de las provincias vascas, pues eran famosas a nivel internacional. Matthew Sutcliffe, autor en 1593, de The Practice, Proceedings and Law of Arms, decía así «La pica que yo quisiera, a ser posible, es la de fresno español de 20 a 22 pies de largo». El italiano Andrea Navagero en su Viaje por España destaca el cultivo de fresno en la zona para emplearse en las picas de los infantes que se utilizaban en los conflictos bélicos (Alfaro, 1976, pp. 212-213).

\section{d) Gastos y financiación para hacerlos frente}

Vamos a intentar proporcionar los datos más fiables referidos a los gastos derivados de la formación de la compañía y cómo se llevó a cabo su financiación. Ya se

\footnotetext{
40 AHPA, Protocolos Notariales, 4409, Francisco de Salvatierra, escribano, fol. 198 r. Vitoria, 28 de diciembre de 1569

$41 \mathrm{AMBu}, \mathrm{C} 2-8-16$, Documentos de 1570 (sin catalogar). 30 de enero de 1570.

42 AMBu, Documentos Guerra de Granada, C2-8-15-4. Marquina, 24 de marzo de 1570

43 AMBu, Documentos Guerra de Granada, C2-8-15-4. Marquina, 22 de abril de 1570.

44 AMBu, Documentos Guerra de Granada, C2-8-15-4. Burgos, 8 de abril de 1572.

$45 \mathrm{AMBu}$, Asuntos de guerra, milicianos y milicias, C2-8-15-7. Burgos, 18 de enero de 1570.
} 
ha apuntado cómo se determinó que las pagas de los dos primeros meses fueran por cuenta de la Hacienda Real. El tesorero general, Melchor de Herrera, entregó la paga de un mes a Cristóbal de Nájera para su abono a la compañía burgalesa ${ }^{46}$. La hacienda municipal debía hacer frente a dos meses de paga de la compañía que supuso más de 1.500.000 maravedíes, puesto que debía tener el mismo sueldo que una compañía que militase en Italia, con la equivalencia de 10 reales cada escudo. Parece que no se aplicó en todos los casos; a la hora de contabilizar los gastos por hombres, la ciudad señaló haber abonado al alférez 500 r. (muy por encima de lo estipulado); al sargento, 200 r.; a los cabos de escuadra 77 r. y a los infantes 40 r., 44 r., y 80 r. a los soldados viejos ${ }^{47}$. El montante por un mes de soldada ascendió a 838.488, lo que suponía una diferencia de 73.488 mrs. entre lo que contabilizó el regimiento y lo que debía haber supuesto, y que se justifica por ser el único medio para poder reunir a la gente necesaria.

Tabla 3. Cuenta del gasto que hizo la ciudad de Burgos para levantar los 531 infantes

\begin{tabular}{|c|c|c|c|}
\hline Concepto & Cantidad & Precio mrs./unidad & Maravedíes \\
\hline Ballestas con sus aderezos y jaras & 125 & 1.000 & 125.000 \\
\hline Morriones de primer coste, estofarlos y limpiarlos & 500 & & 152.040 \\
\hline Picas & 125 & 340 & 425.00 \\
\hline Coseletes de infantería realizados por el armero Pedro de Trigueros & 50 & $3.437,5$ & 121.875 \\
\hline Petos con espaldares & 100 & 1.000 & 100.000 \\
\hline Petos tranzados & 100 & 680 & 68.000 \\
\hline Arcabuces comprados en la ciudad & 54 & 1.000 & 54.000 \\
\hline $\begin{array}{l}\text { Arcabuces que Hernando de Aguirre, criado de su majestad dio a } \\
\text { Trigueros }\end{array}$ & 200 & 748 & 149.600 \\
\hline $\begin{array}{l}\text { Arcabuces que mandó hacer Trigueros, antes de su majestad manda- } \\
\text { ra dar los } 200 \text { anteriores }\end{array}$ & 270 & 782 & 211.140 \\
\hline 353 libras de pólvora y 100 libras de cuerdas dadas a los soldados & & & 41.106 \\
\hline $\begin{array}{l}\text { Acarreo de las armas desde Vizcaya hasta la ciudad de Burgos y el } \\
\text { transporte de las enviadas a Granada }\end{array}$ & & & 56.000 \\
\hline $\begin{array}{l}\text { Estancia de Pedro de Trigueros en la provincia de Vizcaya y otras dos } \\
\text { personas que le ayudaron }\end{array}$ & & & 54.000 \\
\hline La paga a los 534 infantes enviados* & & & 838.488 \\
\hline $\begin{array}{l}\text { Préstamo que se hizo al capitán Sancho de Tovar, a devolver en dos } \\
\text { años }\end{array}$ & & & 375.000 \\
\hline $\begin{array}{l}\text { Hacer la bandera, vestir el pífano y tambores, en correos enviados } \\
\text { y otros gastos }\end{array}$ & & & 233.425 \\
\hline $\begin{array}{l}\text { Pago del alojamiento de los soldados reclutados en los lugares de la } \\
\text { jurisdicción y comarcar hasta su partida a Granada }\end{array}$ & & 25 & 300.000 \\
\hline Total & & & 2.922.174 \\
\hline
\end{tabular}

Fuente: AMBu, C2-8-15-4. *El importe sería el de un mes, habría que duplicarlo.

46 AMBu, Libro de Actas, 1569, 2 de enero de 1570, fol. 220 v.

47 AMBu, Libro de Actas, 1570, 30 de diciembre, fol. 218 r. 
El regimiento burgalés recibió una cédula real, en el mes de febrero, en la que se le reclamaba el sueldo de los soldados y determinó que se enviara el dinero a Córdoba $^{48}$. Aunque no debió materializarse puesto que a finales de año ${ }^{49}$ se le exigía el pago de 1.390.600 mrs. por este concepto. Los responsables de la ciudad defendieron no realizar el abono por la gran cantidad de dinero que se había invertido en la formación de la compañía (vid. tabla 3).

Pedro de Trigueros había recibido varias partidas de dinero para hacer frente a los gastos de la compra de armas y defensas que hicieron un monto de 703.000 maravedíes (cantidad inferior a la real si tenemos en cuenta el cuadro anterior (vid. tabla 4$)^{50}$. De este montante, Trigueros no pudo justificar 92.837 maravedíes y se le pidieron responsabilidades. Se negociaron dos rebajas: la primera de 66.096 maravedíes si traía a la ciudad 108 petos que había pagado; la segunda, de 4.000 maravedíes, si traía justificante de haberlos abonado a Juan Martín de Marcoyda por haberle ayudado a comprar las armas. Pedro de Trigueros, como principal, y Juan Martín de Alquiza, mayordomo de artillería como su fiador, se comprometieron a hacer entrega de los petos, de la carta de pago del salario de Marcoyda y de un coselete de infante valorado en 2.432 maravedíes para el día de Navidad de 1571, a la vez que solicitaba el abono de los costes del transporte, de las cestas, marga y cordeles para el mismo ${ }^{51}$. El mayordomo de artillería quedó libre de la obligación como fiador, al asumir este papel el mercader de paños y sedas burgalés Pedro de la Torre ${ }^{52}$.

Tabla 4. Envíos de dinero a Pedro de Trigueros para adquirir armamento

\begin{tabular}{|l|l|c|}
\hline $\begin{array}{c}\text { Localidad de entrega } \\
\text { si se especifica }\end{array}$ & \multicolumn{1}{|c|}{ Quien entrega el dinero } & Maravedíes recibidos \\
\hline Burgos & Juan Ortega de la Torre, cambista & 40.000 \\
\hline Marquina & Vivanco, correo de la ciudad & 136.000 \\
\hline & Vivanco, correo de la ciudad & 272.000 \\
\hline Vitoria & Hernando de Zárate & 149.600 \\
\hline & Sebastián Ruiz de Almansa, diputado de la ciudad & 102.000 \\
\hline Marquina & Arcabuceros que debían hacer, de nuevo, 70 armas & 3.400 \\
\hline Total & & 703.000 \\
\hline
\end{tabular}

Fuente: AMBu, Libro de Actas, 1570.

48 AMBu, Libro de Actas, 1570, 14 de marzo, fol. $61 \mathrm{v}$.

49 AMBu, Libro de Actas, 1570, 30 de diciembre, fol. 357 r.

50 AMBu, Libro de Actas, 1570, 11 de marzo, fol. 228 r.

51 AMBu, HI-959, sin foliar, Burgos, 21 de abril de 1571.

52 AMBu, HI-959, sin foliar, Burgos, 1 de junio de 1571. 
El capitán Tobar y su hijo Juan habían recibido 1.000 ducados prestados con la obligación de devolverlos ${ }^{53}$, pero al regreso de Granada no podía cumplir su compromiso, por lo que el regimiento decidió hacer una petición al Consejo de Castilla para que, en compensación por los servicios prestados por Tovar, le fuera remitido esa cantidad y así la pudiera devolver a la ciudad ${ }^{54}$.

Para poder afrontar los gastos derivados de la formación de la compañía, armamento, etc., la ciudad se vio obligada a tomar varios censos (con facultad real): 4.000 ducados sobre los propios de la ciudad ${ }^{55} \mathrm{y}$, ante la imposibilidad de abonar la paga a los reclutas, otros 6.000 ducados $^{56}$. El 7 de diciembre de 1569 se acordó tomar dos censos: el primero ofrecido por Gregorio de Santa María por valor de 4.000 ducados (1.500.000 maravedíes), y por el que recibiría anualmente 107.142 maravedíes en dos pagos hasta su redención; un segundo censo ofrecido por Bernardino de Santa María, por el mismo importe e intereses ${ }^{57}$. Para hacer frente a estos censos se debían aplicar repartimiento y sisas de vino hasta condonar la deuda, puesto que los propios y rentas de la ciudad ya estaban hipotecadas ${ }^{58}$.

Ambas cantidades se habían gastado ya a comienzos de 1570, por lo que era necesario buscar más fondos a través de estos conductos ${ }^{59}$. El 4 de marzo de 1570 se concedió licencia para tomar a censo sobre los propios otros 4.000 ducados de vellón y en la misma forma otros 1.402 .000 maravedíes, lo que suponía que se podía endeudar en otros 2.902.000 maravedíes $^{60}$. Miembros de las principales familias de comerciantes se apresuraron a ofrecer liquidez para este fin tal (vid. tabla 5) - los Santa María, que aportaron 3.000.000 mrs., algo más del 68\%; los Salamanca, 1.120.000 mrs. el 25,45\%, y el resto la viuda de Quintanadueñas — ${ }^{61}$. El interés aplicado en todos los casos fue del 7,14\% el tipo máximo legal, y el que se estaba dispuesto a pagar cuando urgía conseguir dinero.

53 AMBu, C2-8-15-4. Documentos Guerra de Granada, Burgos, sin fecha.

$54 \mathrm{AMBu}$, Libro de Actas, 1570, 28 de noviembre, fol. $341 \mathrm{v}$.

55 AMBu, Libro de Actas, 1569, 28 de noviembre, fol. $188 \mathrm{r}$.

56 AMBu, Libro de Actas, 1569, 3 y 7 de diciembre, fol. 193 v., fol. 201 r.

57 AMBu, Libro de Actas, 1569, 7 de diciembre, fol. $197 \mathrm{r}$.

58 AMBu, C2-8-15.4. Documentos Guerra de Granada. Madrid, 20 de agosto de 1571.

59 AMBu, Libro de Actas, 1570, 7 de enero, fol. 13 r,

60 AMBu, HI-4299. Madrid, 4 de marzo de 1570.

$61 \mathrm{AMBu}$, Libro de Actas, 1570, 14 de marzo, fol. 61 v-70 v.; AMBu, HI-1560. Burgos, 14 de marzo de 1570. El censo de Petronila de Aguilar se redimió el 14 de diciembre de 1571. 
Tabla 5. Censos tomados para sufragar los gastos de la guerra de Granada

\begin{tabular}{|l|l|c|c|}
\hline \multicolumn{1}{|c|}{ Año } & & Principal en maravedíes & Intereses anuales 7,14\% \\
\hline 1569 & Gregorio de Santa María & 1.500 .000 & 107.142 \\
\hline 1569 & Bernardino de Santa María & 1.500 .000 & 107.142 \\
\hline 1570 & Francisco de Salamanca & 560.000 & 40.000 \\
\hline 1570 & $\begin{array}{l}\text { Isabel de Salamanca, viuda de Alonso de } \\
\text { Maluenda }\end{array}$ & 350.000 & 25.000 \\
\hline 1570 & $\begin{array}{l}\text { Leonor de Salamanca, hija de Alonso de } \\
\text { Maluenda e Isabel de Salamanca }\end{array}$ & 210.000 & 15.000 \\
\hline 1570 & $\begin{array}{l}\text { Petronila Aguilar, viuda de Gaspar de Quinta- } \\
\text { nadueñas }\end{array}$ & 280.000 & 20.000 \\
\hline & & 4.400 .000 & 314.284 \\
\hline
\end{tabular}

Fuente: AMBu, Libros de Actas de 1569 y 1570.

Teniendo en cuenta la tabla ofrecida por el regimiento de los gastos originados con una total de 2.922.174 mrs., a lo que consideramos se debe sumar otro mes de la soldada por importe de 838.488 , suponía un total de 3.760 .662 mrs.; quedaría libre de los censos tomados la cantidad de $639.338 \mathrm{mrs}$.

\section{El honor de la ciudad}

Atendiendo al deseo del monarca, el contingente burgalés debía de estar en la ciudad de Granada el 31 de diciembre de 1569 pero no se pudo cumplir por la dificultad a la hora de reclutar hombres. El capitán Sancho de Tobar recibió una notificación, el 7 de enero de 1570, en la que se le ordenaba partir y «comenzar a caminar» con la gente que hubiera conseguido hasta esa ciudad. Las actas capitulares recogen el protocolo y la solemnidad de dos momentos claves: la bendición de la bandera y el desfile de esa partida.

\section{a) La bendición de la bandera}

Los representantes de la justicia y del cabildo de la ciudad se trasladaron a la casa del Condestable, donde se alojaba el señor corregidor, y desde la puerta principal que miraba al Mercado Mayor se dirigieron a las casas de Bernardino de Salinas, donde se hospedaba el capitán y estaba la bandera. A la entrada de la calle de la Puebla se situó el capitán — arcabuz al hombro, espada y la banda roja — acompañado, en ambos lados, de muchos caballeros y de los señores principales que llevaban capa y espada, seguido de otros caballeros que deseaban salir con él como soldados. Les seguían casi 200 arcabuceros, dispuestos de cinco en cinco, en medio de los cuales se 
situaba el alférez — vestido de colorado y bordado y guarnecido de oro sobre terciopelo y raso carmesí-, con la bandera y detrás los pífanos y atambores. La bandera era amarilla y negra con la cruz colorada «a manera de aspa», colores más lucidos y vistosos que los antiguos morado y pardo.

Al llegar el capitán al encuentro de la justicia y regimiento de la ciudad hubo una gran salva de arcabucería, tras la cual, el capitán, caballeros y gente principal, seguidos de los soldados y arcabuceros, en medio de los cuales iba el alférez con la bandera, detrás el sargento y algunos cabos de escuadra, y tras ellos los señores justicias y regidores. Los miembros del regimiento iban de dos en dos, los más recientes delante y los más antiguos detrás, y luego el escribano mayor y alcaldes mayores de esta manera: los señores Andrés Gutiérrez, alcalde mayor, e Íñigo de Zumel Saravia, escribano mayor, detrás de los regidores; detrás Jerónimo de Matanza y Pedro García Orense, alcaldes mayores y en medio el señor corregidor, Alonso de Carriazo, y su teniente; y por último, se incorporó toda la gente del pueblo que quiso ir tras la bandera. Se recorrieron las calles de La Puebla. San Juan, San Gil, San Llorente, Coronería y Azogue, por donde se bajó a la plaza de la fuente, delante de la puerta real de la catedral de Santa María. Durante todo el recorrido los arcabuceros estuvieron haciendo salvas, hasta que se llegó a la catedral, en donde se paró por miedo a que se quebraran las vidrieras (vid. plano 1).

Las campanas de la seo repicaron en señal de fiesta y regocijo. En la puerta real esperaban menestriles altos con música de capilla y los cantores, los señores del cabildo catedralicio con su cruz y luminarias, preste, diácono, subdiácono y seis caperos revestidos de rico brocado y los demás con sus sobrepellizas. Allí permanecieron hasta que entraron el capitán Tobar, los soldados y la bandera, los justicia y regimiento de la ciudad, que tenían su asiento reservado en la capilla mayor. Los soldados se dispusieron en dos hileras desde el coro al altar mayor; el capitán, los caballeros y la gente principal, tuvieron su sitio sobre las gradas, junto al altar mayor, al lado de la epístola, y los que no cupieron se situaron al otro lado; la bandera se depositó junto al altar mayor al lado del evangelio durante la celebración de la misa mayor; y en el crucero hombres y mujeres principales de la ciudad. La Eucaristía fue celebrada con los seis caperos y con la música de menestriles y cantores con mucha solemnidad y luminarias como se hacía en fiestas y días solemnes.

Tras finalizar la celebración, el alférez tomó la bandera y la tendió encima de las gradas junto al altar sobre una alfombra, se puso de rodillas acompañado del sargento, otros oficiales y de los soldados más destacados, se rezó una letanía cantada, otras oraciones y salmos para después, el obispo de Sidonia, canónigo de la Santa Iglesia, revestido de pontifical, con el preste, diácono, subdiácono, caperos y señores del dicho cabildo, con el misal dijo ciertas oraciones y bendiciones sobre la bandera, a la que fue echando agua bendita. 
Una vez bendecida la bandera, el capitán y el alférez besaron la mano del obispo, quien les dio un abrazo y paz, a cada uno según su grado para luego ofrecer la bandera al capitán, y éste entregarla al alférez. Todos los actos estuvieron amenizados con música. El cabildo catedralicio salió en procesión hasta la puerta real para despedir al capitán y a los componentes del regimiento. Posteriormente desfilaron desde la calle de la Cerería a la puerta del Sarmental, Cerrajería a Salinería, la Llana, calle de San Lorenzo y de allí, por el camino y orden que habían seguido hasta dejar la bandera en su lugar, siempre acompañados de salvas de los arcabuceros. Los señores justicia y regimiento acompañaron al señor corregidor hasta su posada y desde allí se fueron cada uno de los miembros del cabildo municipal a sus casas.

El recorrido se llevó a cabo por las principales calles de la ciudad en aquellos momentos; calles que recorrieron los monarcas cuando visitaron la ciudad, como Ana de Austria, en octubre de 1570, en su camino para encontrarse con su esposo Felipe II (Sanz, 1983, pp. 375-396), o los cortejos fúnebres en las exequias burgalesas de los Austrias (Melgosa Oter, 2019, pp. 1298-1302).

\section{b) El desfile de la partida hacia Granada}

El 17 de enero, a pesar de la orden de tener que estar en la ciudad de Granada, aún se encontraban en Burgos. Durante esos días, el capitán Tobar había manifestado la necesidad de llevar con su gente de la compañía a un cirujano asalariado por la ciudad, y que los ballesteros, en vez de portar ballestas llevasen arcabuces, ya que eran armas más eficaces en el combate ${ }^{62}$.

El jueves 19, por la tarde, Tobar, con su compañía, salió de su posada, acompañado por los señores justicia y regimiento de la ciudad camino a Granada. (vid. plano 2) Salieron por su orden desde la Plaza Mayor y desde allí por la calle de La Puebla, el barrio de San Juan y la rúa de San Gil a San Llorente, desde donde bajaron por la Pellejería, La Llana, Sombrerería, Sarmental, puerta de Santa María, Vega, Calera, eras de Santa Clara hasta llegar al monasterio de San Agustín. Hasta este punto fueron acompañados por los más ilustres burgaleses y representantes de la ciudad, y allí se despidieron. El capitán y todos sus hombres entraron al monasterio para realizar una visita al Santísimo Crucifijo de San Agustín, el Cristo de Burgos que hoy se puede contemplar en la catedral, y salieron para seguir camino hasta la población de Arcos, donde se acordó que se hiciera «muestra y alarde» de la gente que iba bajo su bandera.

La villa de Arcos acogió al corregidor, el licenciado Alonso de Carriazo, a Pedro García de Orense, alcalde mayor, a Íñigo de Zumel Saravia, escribano mayor, y a Andrés de Maluenda, regidor, que habían sido elegidos diputados para lo tocante 
al reclutamiento de los hombres. Estos se reunieron con el capitán Sancho de Tobar y con Cristóbal de Nájera, pagador de su majestad, en la iglesia de San Miguel de la localidad, y tras haber oído misa, acordaron convocar a toda la gente de guerra allí donde comenzó el registro de cada uno de ellos, haciendo entrega de la paga según su categoría. Junto a Nájera estuvo Francisco de Castellanos (contador de la ciudad de Burgos), vecinos de la ciudad y de la villa de Arcos, algunos capitanes y alférez y soldados de las compañías que entonces había en esta comarca.

El viernes, 22 de enero, la compañía partió hacia la ciudad de Granada, para presentarse ante don Juan de Austria. Tras la partida de los hombres, el cabildo catedralicio determinó que se celebraran procesiones todos los domingos de Cuaresma después de las vísperas para pedir por la victoria contra los turcos y asignó medio real por prebenda a todos los asistentes ${ }^{63}$. El monarca expidió una real cédula en la que promovió, en todo el territorio, la creación de la cofradía de la Fe Católica con el fin de que las cuotas de entrada y limosnas de los cofrades pudieran ayudar a la defensa de la fe y a la reducción de los moriscos sublevados. El cabildo nombró por su mayordomo a Miguel de Mena ${ }^{64}$.

Plano n. ${ }^{\circ}$ 1. Itinerario del desfile de las autoridades municipales y de la compañía del capitán Sancho de Tovar para bendecir la bandera en la seo burgalesa el día 17 de enero de 1570

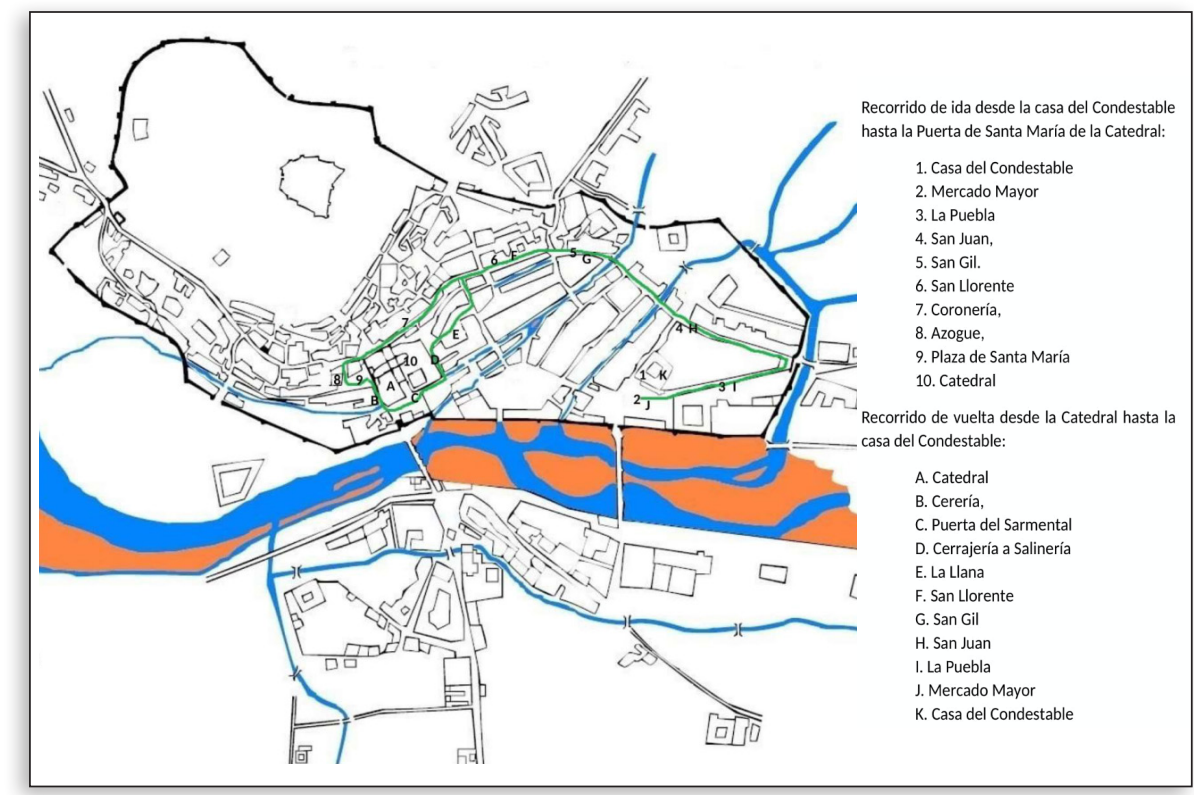

$63 \mathrm{ACBu}$, Registro 56, fol. 351 v. 6 de febrero de 1570.

$64 \mathrm{ACBu}$, Volumen 63, fol. 4-5. Copia auténtica ante Juan Ortega, notario. 6 de febrero de 1570 
Plano n. ${ }^{\circ}$ 2. Recorrido del capitán don Sancho de Tovar desde la ciudad de Burgos camino de Granada. 19 de enero de 1570

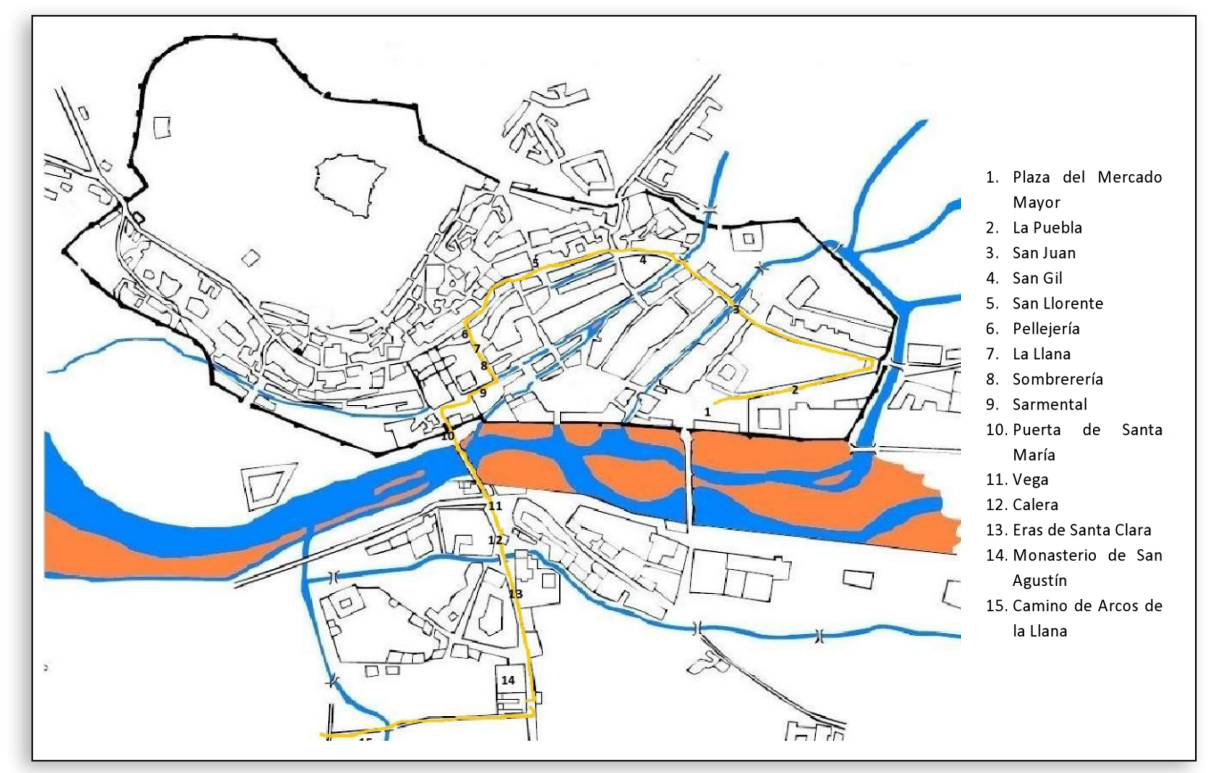

\section{El papel de la compañía a las órdenes de don Juan de Austria}

Don Juan de Austria fue nombrado capitán general del ejército cristiano para combatir a los rebeldes en diciembre de 1569. Su primera actuación tuvo lugar en Galera, localidad que opuso una gran resistencia pero que fue conquistada el 10 de febrero. Se notificó a las villas de Úbeda, Baeza y Jaén, localidades por donde tenían que pasar alrededor de dos mil efectivos procedentes de Castilla y Toledo, que les informasen de que debían dirigirse al campo de don Juan de Austria y no a la ciudad de Granada (Mármol Carvajal, 1797, p. 259). Entre aquellos hombres se encontraban los burgaleses, que se acercaban con bastante retraso, pues parece que el 31 de enero aún se encontraban en Atienza (Guadalajara), hecho tan sólo explicable por el deseo de llegar al campo de batalla bien armados (López Mata, 1957, pp. 355-356).

A primeros de marzo llegó en contingente burgalés para ponerse a las órdenes del capitán general quien tomó la decisión de adscribirlo al tercio de Nápoles venido a la península con Luis de Requesens y cuyo maestre de campo era Pedro de Padilla. Justo antes de su llegada, el ejército de don Juan de Austria había vencido a los rebeldes en Serón y se comenzó la campaña militar sobre el Almanzora, apoyada por la incorporación del importante contingente burgalés (Sánchez Barrios, 2000, p. 531). Desde los primeros momentos las condiciones fueron muy duras, y así lo expuso el capitán Tobar en una carta de 7 de marzo cuando manifestó: 
hace el tiempo de nieves y aire tal que temo hemos de adolecer todos, porque no nos desnudamos y de tres en tres noches hacemos guardia. Los bastimentos son muy caros, las pagas se dilatan [...]. Suplico a vuestra señoría que cuando se acaben de cumplir estos dos meses esté acá el pagador con dineros... porque de otra manera los soldados no podrán servir ni yo les tendré a mi cargo [...], en Purchena está toda la pujanza de los moros de este río de Almanzor [...], el lugar es fuerte. Parecen muestras de que nos querrán dar batalla, sería buena nueva para los soldados, porque, como digo mueren de hambre (López Mata, 1957, p. 357).

La campaña no estaba resultando nada fácil. Felipe II, en el mes de marzo, volvió a solicitar al cabildo de la catedral de Burgos que se continuara orando por la victoria de los cristianos contra los turcos, que habían tomado La Goleta (Túnez) y amenazaban con acudir a socorrer a los moriscos de Granada, por lo que era necesario continuar con la celebración de procesiones y plegarias ${ }^{65}$.

El capitán redactó otra carta al regimiento burgalés, desde el campo de Purchena $^{66}$, el 26 de marzo de 1570, en la que informaba cómo se había desarrollado el combate. Los miembros de la compañía estuvieron presentes en la jornada de Tíjola, en donde trabajaron en las trincheras y batería, pasando «ruines días y noches». La bandera de la ciudad burgalesa fue la primera que estuvo en la vanguardia (Hurtado de Mendoza, 1776):

El día siguiente salió del alojamiento: los enemigos mostrándose en ala como es su costumbre, i danto grita acometieron a Don Pedro de Padilla (a quien aquel día tocaba la vanguardia) con determinación a lo que se veía, de dar batalla. Eran seis mil hombres entre arcabuceros i ballesteros, algunos con armas enhastadas [...] Salió a ellos don Pedro con sus banderas y con los aventureros que llevaba el marqués de la Favara.

El combate fue muy duro. Tobar informó de que murieron unos 300 moros y unos 200 soldados burgaleses, y el resto de la compañía quedó maltrecha. El capitán quedó «sin caballo ni acémila ni dinero», y se quejaba de no haber recibido a través del pagador los casi 500.000 maravedíes que tenía en créditos en Granada, por lo que solicitaba a la ciudad de Burgos el envío de los 500 ducados que se comprometieron a prestarle.

$65 \mathrm{ACBu}$, Registro 56, fol. 372, 13 de marzo de 1570; y ACBu, Libro 64, fol. 780, 6 de marzo de 1570.

66 AMBu, C2-15-4, Documentos Guerra de Granada. Campo de Purchena, 26 de marzo de 1570. 
Un mes más tarde, el capitán envió otra carta desde el campo de Terque ${ }^{67}$ (Almería), donde hacía hincapié en el hambre padecido y en las bajas sufridas en su compañía. Reprochaba al regimiento que no le enviara el dinero para socorrer a los soldados; era necesario contar con aquel dinero para aumentar el número de hombres con nuevos alistamientos tras las bajas sufridas, puesto que debía pagar 500 hombres y no los había. También apuntaba que, a pesar de las bajas, su compañía era «la mayor de este campo y no la menos estimada», lo que hace pensar en la crueldad de la batalla y la gran pérdida de vidas cristianas. Aquella terrible situación provocó que pidiera licencia a la ciudad para dejar de ser su capitán y que la compañía estuviera directamente bajo las órdenes de don Juan, puesto que «quería estar libre de muchas pesadumbres que hay en este cargo»; petición que no se hizo efectiva.

Tobar manifestaba que el campo del duque de Sessa — don Gonzalo Fernández de Córdoba y Fernández de Córdoba-, que se encontraba en Adra, reunía entre 7.000 y 8.000 hombres y un aumento de efectivos podría suponer una victoria. También señalaba que las dos cargas de armas que le habían llegado ya no eran necesarias porque se perdían por los barrancos y en aquella orografía tan montañosa; era «mejor andar tras ellos a cuchilladas». El balance que hacía de sus hombres era desalentador y lo resumía así: «de los de Miranda y Villahoz no han quedado diez y de esa ciudad casi ninguno» ${ }^{68}$.

El capitán burgalés, el 23 de junio, informó encontrarse en Cob de Andarax, donde «han muerto, enfermado e ido la mayor parte de los soldados, de los de la ciudad quedaban menos de ochenta, de los cuales treinta se encontraban enfermos y partirían a sus casas al día siguiente». Los capitanes de Madrid y Toledo, en esos momentos, con licencia de don Juan de Austria habían desarbolado sus banderas y los pocos soldados que les quedaban vivos se habían repartido entre otras compañías, pero Tobar no estaba dispuesto a hacer lo mismo mientras le quedara un soldado bajo sus órdenes; habló bien de sus soldados, y de su cumplimiento del deber hasta que el hambre y las enfermedades los habían vencido (López Mata, 1957, p. 363). La compañía que tanto esfuerzo había costado formar era ya un espejismo, todo el esfuerzo humano y económico se desvanecía. A pesar de la práctica desaparición de la compañía burgalesa, don Juan de Austria envió una carta al regimiento de la ciudad desde Cob de Andarax, en la que relataba cómo Sancho de Tobar había llegado a su campo con una compañía de infantería tan bien armada que, sin hacer agravios, había sido la mejor, y junto al capitán había venido su hijo don Juan de Tobar. La compañía había participado en asaltos, correrías, escoltas y en todas las demás misiones enco-

67 AMBu, Asuntos de Guerra, milicianos y milicias, C2-8-15-7. Campo de Terque, 28 de abril de 1570 .

68 AMBu, Asuntos de Guerra, milicianos y milicias, C2-8-15-7. Campo de Terque, 28 de abril de 1570 . 
mendadas, por lo que, a causa de los «accidentes de la guerra» y por enfermedades, la compañía se había reducido tanto que se determinó dar licencia a los pocos que quedaban vivos para que pudieran regresar a sus casas ${ }^{69}$.

El 30 de julio se decidió dar pasaportes a los soldados que quedaban bajo la bandera para que volvieran a sus casas, y que la bandera fuera guardada en un cofre para entregarla al regimiento. Los soldados licenciados partirían hacia Guadix, y desde allí a Granada para seguir su camino hacia Burgos ${ }^{70}$. El capitán no regresó a Burgos hasta noviembre de 1570, entró en el Regimiento e informó de las actuaciones de la compañía al servicio de su majestad, como bien expresó don Juan de Austria. También realizó la entrega de la bandera, pero los representantes de la ciudad, en agradecimiento por el valor de su persona y por cómo había llevado a su gente, no la quisieron recibir porque las banderas eran de los capitanes y debía quedar en su $\operatorname{poder}^{71}$.

\section{Conclusiones}

Uno de los principales objetivos de gobierno de Felipe II fue, como él mismo expuso, «que en estos reinos y sus estados se sostenga la santa Fe y la religión católica y obediencia y autoridad de la Santa Sede apostólica romana» ${ }^{72}$. Así lo manifestó en la convocatoria que envió, en el mes de marzo de 1570, a los justicias y regimiento de la ciudad burgalesa para que sus procuradores acudieran a cortes a la ciudad de Córdoba; el monarca quería estar cerca de donde se estaba librando la batalla. Pero las alteraciones que se estaban sucediendo en los estados de Flandes, el levantamiento de los moriscos de Granada, la ayuda prestada al rey de Francia para su lucha contra los herejes y el esfuerzo realizado en los nuevos territorios americanos obligaron a la hacienda real a asumir unos gastos ingentes cuando se encontraba exhausta, consumida y sin rentas, por lo que no tuvo más remedio que volver a recurrir a sus súbditos y naturales para que contribuyesen con el socorro de los ejércitos. El monarca también se encontraba en una situación personal muy delicada al haber perdido a su hijo y heredero, el príncipe Carlos, y a su tercera esposa, Isabel de Valois; y la obligación de tener un hijo varón para su sucesión tuvo como consecuencia su cuarto matrimonio con su sobrina Ana de Austria, hija de María de Austria y Portugal y de Maximiliano II de Habsburgo. Las cortes celebradas en la ciudad de Córdoba, entre los meses de febrero y abril (interrumpidas por el desarrollo de los acontecimientos), trataron el tema económico: el otorgamiento del servicio ordinario y extraordinario

69 AMBu, Libro de Actas, 1570, 11 de agosto, Andarax 31 julio de 1570

70 AMBu, Libro de Actas, 1570, 11 de agosto, Cob de Andarax, 30. de julio de 1570.

71 AMBu, Libro de Actas, 1570, 23 de noviembre, fol. $338 \mathrm{v}$.

72 AMBu, Libro de Actas, 1570, 15 de marzo de 1570, fol. 73 r-78 v. 
y el servicio por la nueva boda del rey con Ana de Austria ${ }^{73}$. Como hemos apuntado al comienzo de este trabajo (vid. Tabla 1), la ciudad aún tenía deudas pendientes del periodo $1565-1570$ por un montante de $2.177 .521 \mathrm{mrs}$., a lo que habría que sumar los gastos originados por el reclutamiento de hombres y la compra de armas para auxilio contra el levantamiento de los moriscos, que se ha calculado en $2.922 .174 \mathrm{mrs}$, pero aún se exigiría por parte de Felipe II, que su cuarta esposa fuera recibida en la ciudad como se merecía, en octubre de 1570. Tal acontecimiento supuso un gasto de 1.654.400 mrs., siendo necesario acudir a impuestos extraordinarios para poder hacer frente a los gastos, financiación que recayó, una vez más, en las clases más populares. Estos tres capítulos sumaban un montante de 6.754.095 mrs., una deuda difícil de afrontar (Pereda, 2021).

Como se ha venido exponiendo, Burgos realizó un gran esfuerzo para poder formar la compañía y armarla; y pocos tuvieron la suerte de regresar con vida. Tras la victoria cristiana, se comenzó un proceso de expulsión del reino de Granada y de reparto por todo el territorio de Castilla para así evitar nuevas revueltas; también se inició el proyecto de repoblación en los territorios apaciguados. A Burgos, en principio, le fueron asignados 1.000 moriscos, pero el corregidor de la ciudad, como su representante, alegó que el número era excesivo y solicitó que, en la medida de lo posible, no fuera enviado ninguno (Gutiérrez Alonso, 1991, p. 91). Al parecer se logró el objetivo, puesto que en septiembre de 1571 aún no había sido trasladado ningún morisco — del Adelantamiento de Cazorla - a la ciudad (Vincent, 1984, pp. 53-54).

Con este trabajo se ha intentado proporcionar nuevos datos sobre la aportación que, en hombres y dinero, la ciudad de Burgos y su jurisdicción realizó para que la victoria del ejército, dirigido por don Juan de Austria, fuera una realidad.

\section{AGRADECEMENTOS}

La edición de este trabajo ha sido posible gracias a la ayuda del Programa de Grupos de Potencial Crecemento concedida por la Consellería de Cultura, Educación e Universidade da Xunta de Galicia al GI-1921 de la USC (Referencia: GPC, ED 431B 2021/06). 


\section{Bibliografía}

AldeCoA, Antonio (1976), «Influencia de los armeros vascos en la armería española», en III Semana de Antropología Vasca, Bilbao, vol. 2.

Alfaro, Félix (1976), «Armería en las Vascongadas y Navarra», en III Semana de Antropología Vasca, Bilbao, tomo 2, pp. 211-219.

AzPIAZu, José Antonio (1994), «Fabricación y comercialización de armas en el Valle del Deba (1550-1600)», Vasconia, Cuadernos de Sección. Historia-Geografía (22), pp. 9-72.

CArrión Arregui, Ignacio Ma . (1998), «La crisis del siglo XVII y la producción de armamento en Gipúzkoa», Revista de Dirección y Administración de Empresas (7), noviembre, pp. 21-31.

Castillo Fernández, Javier y Muñoz Buendía, Antonio (2000), «La Hacienda», en Manuel Barrrios Aguilera (ed.), Historia del Reino de Granada, vol. II. La época morisca y la repoblación (1502-1630), Granada, Universidad de Granada, pp. 101-177.

Contreras Gay, José (1997), «Las milicias de socorro del Reino de Granada y su contribución a la defensa de la costa después de 1568», en Actas del Congreso la Frontera Oriental Nazarí como Sujeto Histórico (S. XIII-XVI), Almería, Instituto de Estudios Almerienses, pp. 613-622.

Cuesta Nieto, José Antonio (2012), «Los campesinos en Castilla la Vieja, hombres de armas», en Pérez Álvarez, María José y Marín García, Alfredo (eds.), Campo y campesinos en la España Moderna. Culturas políticas en el Mundo Hispánico, Madrid, FEHM, pp. 793-812.

Domínguez Ortiz, Antonio y Vincent, Bernard (1984), Historia de los Moriscos. Vida y tragedia de una minoría, Madrid, Alianza Editorial.

Fernández Álvarez, Manuel (1998), Felipe II y su tiempo, Madrid, Espasa Calpe.

González Prieto, Francisco Javier (2006), La ciudad menguada: Población y economía en Burgos. Siglos XVI y XVII, Santander, Universidad de Cantabria.

González Prieto, Francisco y Rodríguez Hernández, Antonio José (2008), «Miranda en Granada. El apercibimiento para las Alpujarras de 1569-1570», Estudios Mirandeses, 27, volumen A, pp. 107-121.

Gutiérrez Alonso, Adriano (1991), «Burgos en el siglo XVI», en Historia de Burgos. Edad Moderna. Vol. 3, Burgos, Caja de Ahorro Municipal, pp. 21-92.

GonzÁlez DíEz, Emiliano (1984), Colección diplomática del concejo de Burgos, Burgos, Instituto de Estudios Castellanos. 
Hurtado de Mendoza, Diego (1776), Guerra de Granada que hizo el rey D. Felipe II contra los moriscos de aquel reino y sus rebeldias, Valencia, en la oficia de Benito Monfort.

Jiménez Estrella, Antonio (2004), Poder, ejército y gobierno en el siglo XVI. La Capitanía General del Reino de Granada y sus agentes, Granada, Universidad de Granada.

JimÉNEZ Estrella, Antonio (2009), «Las milicias en Castilla: evolución y proyección social de un modelo de defensa alternativo al ejército de los Austrias», en Ruiz Ibáñez, José Javier (coord.), Las milicias del rey de España. Sociedad, política e identidad en las Monarquías Ibéricas, Madrid, FCE, pp. 72-103.

Kamen, Henry (1997), Felipe de España, Madrid, Editorial S. XXI.

Larrañaga, Ramiro (1976), «Gremios armeros vascos», en III Semana de Antropología Vasca, tomo 2, Bilbao, pp. 177-208.

López MATA, Teófilo (1957), «Burgos en la sublevación de los moriscos de Granada, 1570», Boletín de la Real Academia de la Historia, tomo 141, cuaderno 1 (julio-septiembre), pp. 332-372.

Mármol Carvajal, Luis (1797), Historia del Rebelión y castigo de los Moriscos del Reino de Granada, Madrid, Imprenta de Sancha.

Melgosa Oter, Óscar Raúl, (2019), «La ciudad como escenario del duelo: el recorrido de los cortejos fúnebres en las exequias burgalesas de los Austrias», en Payo Hernanz, René Jesús et al. (eds.), Vestir la arquitectura, vol. 2, pp. 1298-1302.

Pereda LóPez, Ángela (2021), «La ciudad de Burgos se prepara para la llegada de la reina Ana de Austria, octubre de 1570», en Borreguero Beltrán, Cristina et al. (coords.), A la sombra de las catedrales. Cultura, poder y guerra en la Edad Moderna, Burgos, Universidad de Burgos, pp, 267-281.

Pérez García, Rafael M. y Fernández Chaves, Manuel F. (2012), «La guerra de Granada entre guerra civil y guerra justa», en López Guadalupe, Miguel Luis y Iglesias Rodríguez, Juan José (coords.), Realidades conflictivas. Andalucía y América en la España del Barroco, Sevilla, Universidad de Sevilla, pp. 229-248.

Rodríguez Hernández, Antonio José (2015), Breve Historia de los ejércitos: los Tercios de Flandes, Madrid, Nowtilus.

SÁnchez BARrios, Valeriano (2000), «La guerra de las Alpujarras (1568-1570)», en Barrrios Aguilera, Manuel (ed.), Historia del Reino de Granada, vol. II. La época morisca y la repoblación (1502-1630), Granada, Universidad de Granada, pp. 506-542. 
SAnz, María Jesús (1983), «Festivas demostraciones de Nimega y Burgos en honor de la reina doña Ana de Austria», Boletín del Seminario de Estudios de Arte y Arqueología, tomo 43, pp. 375-396.

Quatrefages, René (2015), Los Tercios, Madrid, Ministerio de Defensa.

TAPIA GARrido, José A. (1990), Historia General de Almería y su provincia, tomo 10, Rebelión y guerra de los moriscos, Almería, Confederación Española de Cajas de Ahorro.

Thompson, I. A. A. (2003), «El soldado del Imperio: una aproximación al perfil del recluta español en el siglo de Oro», Manuscrits (31), pp. 17-38.

VINCENT, Bernard (1984), «L'expulsion des morisques du royaume de Grenade et leur repartition en Castille (1570-1571)», Mélanges de la Casa de Velázquez (6), pp. 211-246. <https://doi.org/10.3406/casa.1970.1019>.

Zabala Aguirre, Pilar (2000), Las alcabalas y la hacienda real en Castilla (siglo $X V I)$, Santander, Universidad de Cantabria. 